\title{
3 Research S quare \\ Left Atrial diameter Index as a prognostic factor for STEMI: a case-control study
}

\section{Ying Zhang}

Jilin University First Hospital

Xiaorong Han

Jilin University First Hospital

\section{Zhongbo Chen}

Chengdu Third People's Hospital

\section{Mengling Peng}

Jilin University First Hospital

Yu Fu

Jilin University First Hospital

Danxi Yang

Jilin University First Hospital

Shanshan Zhou (D 3112656220@qq.com )

Jilin University First Hospital

\section{Research}

Keywords: LAdl, STEMI, left atrium

Posted Date: September 17th, 2021

DOl: https://doi.org/10.21203/rs.3.rs-910519/v1

License: (c) (1) This work is licensed under a Creative Commons Attribution 4.0 International License.

Read Full License 


\section{Abstract}

\section{Background》}

The left atrium has a considerable role in cardiac function because of its unique anatomy and physiological function. We evaluated the role of the size of the left atrium in the prognosis of STEMI by quantifying the left atrium by introducing a left atrial diameter index(LAdl).

\section{Methods:}

This is a retrospective study conducted in a University Affiliated Hospital. Echocardiography is used to evaluate the size of left atrial diameter. It is indexed by body surface(BSA) area to evaluate the significance of LAdl on the prognosis of STEMI.

This study was approved by the medical ethics committee of The First Hospital of Jilin University. All subjects in this trial gave written informed consent.

\section{Results:}

A total of 473 patients with a first STEMI within two years met the inclusion criteria to be included in this study. $\mathrm{LA} \rrbracket \mathrm{OR}=6.945 \rrbracket 95 \% \mathrm{Cl} 1.398 \sim 34.499 \rrbracket P=0.018 \rrbracket$ and $\mathrm{EF} \otimes \mathrm{OR}=0.931 \rrbracket 95 \% \mathrm{Cl} 0.904 \sim 0.960 ; P=0.000 \rrbracket$ were independent risk factors for MACEs.

\section{Conclusion:}

Patients with a first STEMI with a greater LAdl have a greater risk of MACEs than patients with a normal left atrium despite well-established PCI therapies.

\section{Introduction}

As research continues for the left atrium (LA), left atrial enlargement (LAE) has been recognized as a marker of elevated left ventricular (LV) filling pressures and LV diastolic dysfunction.[1] And LAE has been proposed as a biomarker of diastolic blood pressure and a predictor of common cardiovascular outcomes such as atrial fibrillation(AF), stroke, congestive heart failure(HF), and cardiovascular death. [24] However, the complex geometry and irregular fiber arrangement of the LA restrict the quantification of the LA. Although the left atrial volume (LAV) is currently recommended as the standard for quantifying the LA, the left atrial diameter (LAd) is still present in large databases and large epidemiological studies because of its simplicity and ease, and studies have noted that the LAV can be well estimated by the measurement of the LAd.[5] Although there are sex differences in LA, these can be explained almost entirely by body size variation.[6] Currently, the most commonly used method is to index the LAd by body surface area (BSA) to obtain the left atrial diameter index (LAdl) to evaluate LA function.

\section{Methods}




\section{Patient Population}

From January 2017 to August 2018, we retrospectively enrolled 1892 patients who visited The First Hospital of Jilin University for acute ST elevation myocardial infarction(STEMI) treated with emergency percutaneous coronary intervention $\triangle \mathrm{PCI}$, and a final total of 473 cases were enrolled as study subjects.

\section{Inclusion and exclusion criteria}

Patients aged 18-80 years, with a first diagnosis of STEMI and undergoing emergency PCl.

Patients with any of the following conditions were excluded: (a) primary hypertension or secondary hypertension; (b) hepatic dysfunction; (c) renal dysfunction; (d) cardiomyopathy: peripartum cardiomyopathy, uremic cardiomyopathy, congenital heart disease, and other causes of cardiomyopathy; (e) space occupying lesions; (f) definite diagnosis of arrhythmia; (g) refusal to participate in this study, patients with incomplete clinical data and lost to follow-up.

\section{Data collection:}

Demographic data including gender, age, height and weight were collected from the hospital database. Baseline clinical characteristics such as systolic blood pressure(SBP), diastolic blood pressure(DBP), heart rate(HR), smoking history, drinking history, diabetes mellitus history, culprit vessel, Killip class, post discharge medication were registered from the case system. Venous blood samples were taken for examination the following morning after at least 8 hours of inpatient fasting to document leukocyte count, hemoglobin( $\mathrm{Hb}$ ), platelets count, serum uric acid, creatinine(Cre), albumin, total cholesterol(TC), triglycerides, low-density lipoprotein cholesterol(LDL-C), high-density lipoprotein cholesterol(HDL-C), thyroid function, myoglobin(MTO), cardiac troponin I(CTnl), creatine kinase isoenzymes (CK-MB), Ddimer(D-D), B-type natriuretic peptide (BNP).

\section{Echocardiographic examination}

All study subjects were examined by a qualified sonographer within 72 hours of admission. A minimum of $10 \mathrm{~min}$ rest in a quiet, temperature appropriate room was required. All measurements were defined according to the guidelines recommended by the American Society of echocardiography[6]: left atrial internal diameter (LAd), right ventricular diameter (RVd), interventricular septal thickness (IVST), left ventricular posterior wall thickness (LVPWT), left ventricular end diastolic diameter (LVEDd), fractional shortening (FS), left ventricular ejection fraction (LVEF), peak early diastolic velocity (E peak), peak late diastolic velocity (A peak).

\section{Grouping}

The body surface area was calculated applying the Xu Wensheng formula, i.e., BSA $\left(\mathrm{m}^{2}\right)=0.0061 \times$ Height $(\mathrm{cm})+0.0128 \times$ Weight $(\mathrm{kg})-0.1529$. 
$\operatorname{LAdl}\left(\mathrm{cm} / \mathrm{m}^{2}\right)=\operatorname{LAd}(\mathrm{cm}) / \mathrm{BSA}\left(\mathrm{m}^{2}\right)$

According to the suggestion of American Society of echocardiography[6]: the subjects were divided into group A (LAdl $\left.\leq 2.3 \mathrm{~cm} / \mathrm{m}^{2}\right)$ and group B (LAdl $\left.>2.3 \mathrm{~cm} / \mathrm{m}^{2}\right)$.

\section{Follow-up and clinical outcomes}

The study subjects were followed up by telephone after 2 years. The follow-up contents were MACEs, which were defined as: new onset $A F$, new onset $H F$, readmission for coronary artery disease (CAD), and sudden cardiac death (SCD). New onset AF was defined as: AF diagnosed at least 12 leads by ECG. New onset HF was defined as: the occurrence of symptoms and signs of HF, and perfect laboratory and color ultrasound of the heart and related examinations, and HF diagnosed by the attending cardiovascular medicine physician and above. Readmission for CAD was defined as: no medical relief (refractory angina) from angina, recurrent myocardial infarction (MI) and admission for repeat PCI. SCD was defined as: including recurrent ACS, arrhythmia, HF, and other cardiac related deaths. If two or more MACEs occurred in the same study subject, only one MACEs was recorded.

\section{Statistical analysis}

All data of this study were entered and sorted out by Excel, and statistically analyzed by SPSS 26.0 software. In this study, the measurement data were tested for normality and homogeneity of variance. The measurement data conforming to normal distribution and homogeneous variance were expressed by mean \pm standard deviation $( \pm s$ ), the comparison between group A and group B was expressed by t-test, and the measurement data not conforming to normal distribution and heterogeneous variance were expressed by median and interquartile distance $M d(p 25, p 75)$, Mann- Whitney rank sum test was used for the comparison between group A and group B. The counting data were expressed in frequency (rate), and $X^{2}$ test was used for the comparison between the two groups. Since LAdl, GRACE scores and BNP do not conform to the normal distribution, Spearman correlation analysis is used for their correlation analysis. Logistic regression analysis was used to evaluate the risk factors of adverse cardiovascular events in STEMI. Inspection level $a=0.05, P<0.05$, the difference was statistically significant.

\section{Results}

A total of 1892 patients were diagnosed with STEMI and completed emergency PCI in our hospital from January 2017 to August 2018. Of these, 473 (25.00\%) cases met the study criteria and constituted the study cohort. Demographic statistics and baseline clinical characteristics of this patient population are summarized in Table 1. Echocardiographic features are summarized in Table 2. The relationship between LAdl and BNP and the GRACE score are shown in Table 3. A comparison of the occurrence of MACEs between the two groups is presented in Table 4. The results of logistic regression analysis of MACEs are shown in Table 5.

\section{Patient population and baseline clinical characteristics}


In terms of demographic data, the subjects in group B $\left(\mathrm{LAdl}>2.3 \mathrm{~cm} / \mathrm{m}^{2}\right)$ were older $(60.30 \pm 9.56 \mathrm{vs}$ $55.86 \pm 9.77)$, and the difference was statistically significant $(P=0.000)$. The proportion of women in group B (34\%) was slightly higher than that in group A (14\%), and the difference was statistically significant $(P=0.000)$. Moreover, the $\mathrm{BMl}$ of group $\mathrm{B}$ was significantly higher than that of group $\mathrm{A}(24.40$ \pm 1.80 vs $23.79 \pm 2.29, P<0.004)$. Table 1 .

Other baseline clinical characteristics, including past medical history, admission HR and blood pressure, laboratory findings the next morning, culprit vessel, and patient medication after discharge were not statistically significant $(P>0.05)$. Table 1 . The difference was that there were significant differences in Killip grade, GRACE score and stratification between the two groups $(P<0.05)$. Compared with group A, the higher the Killip grade, the higher the proportion of subjects, the more dangerous the GRACE stratification and the more the proportion of subjects in group B. Table 1.

In addition, there was a positive correlation between GRACE score and LAdl. GRACE score increased with the increase of $\operatorname{LAdl}(r=0.284, P=0.000)$. BNP also had a positive correlation with $\operatorname{LAdl}(r=0.107, P]$ 0.020). Table 3.

\section{Echocardiographic features}

All subjects completed echocardiography within 72 hours of admission. It can be seen that the RVD and LVEDd of the subjects in group $B$ are greater than those in group $A$, and the EF and FS are less than those in group $A$. the difference is statistically significant $(P<0.05)$. Table 2 .

\section{MACEs characteristics}

The MACEs of the study subjects in group $B$ were significantly more prevalent than those in group $A$, with a significant difference $(P=0.000)$. Among them, the proportion of subjects with AF and HF in group $B$ compared with group A was significantly higher(Pख0.05).Table 4.

\section{MACEs risk factors}

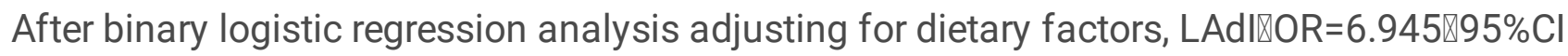
1.398 34.499 $\otimes P=0.018 \rrbracket$ and $\mathrm{EF} \otimes \mathrm{OR}=0.931 \otimes 95 \% \mathrm{Cl} 0.904 \sim 0.960 ; P=0.000$ ॠwere independent risk factors for MACEs. Table 5.

\section{Discussion}

LV volume and EF have long been recognized as hallmark parameters of cardiovascular disease (CVD), in contrast to LA, which has only gradually walked into the popular view in the last decade. There is currently growing interest in the structure, function, and remodeling of the LA, particularly in identifying high-risk individuals through $L A$, diagnosing the underlying disease, and targeting $L A$ as a potential therapeutic target.[7] The mechanical function of the LA is primarily reflected in the three aspects: acting as a reservoir for pulmonary venous blood return when the LV is contracting, as a channel for blood flow 
when the LV is diastolic and as a booster pump assisting in the filling of the LA. $[8,9]$ Not only that, LA has other functions including endocrine functions: synthesis and secretion of atrial natriuretic peptide (ANP);regulatory function: modulation of autonomic activity, control of circulatory reflexes, ANP independent vasopressin (ADH) secretion.[10]

In a clinical study[11] evaluating the morphological and functional impact of physiological aging and gender on the LA, it was found that there was a trend toward progressive enlargement of the LA with age. Other studies have also confirmed that LAE is more common in the elderly.[3,12] This is consistent with the conclusions of our study. Undeniably, with advancing age, the heart undergoes structural and functional alterations even in the absence of other contributing factors.[13] This is usually accompanied by thickening and stiffening of the LV wall, dilation of the LV, and aggravation of the degree of cardiac fibrosis during normal ageing.[14] This may be associated with reduced regenerative capacity of senescent cardiomyocytes,[15] age-related mitochondrial dysfunction, [16]deleterious paracrine effects of senescent cells, and inflammatory responses.[17]

It is worth noting that in this study, female patients are more likely to develop LAE. In studies[3, 18, 19] based on the general population, it was found that female patients are closely related to the increased risk of LAE. Not only that, a study[20] on the relationship between LAd and cardiovascular death in women with AF also reached conclusions about the relationship between female gender and LAE. However, the exact cause of women and LAE is still inconclusive, and some studies speculate that it may be related to a higher degree of inflammation in female patients. There is also other study[21] considering that the higher prevalence of LAE in women may be related to higher systolic blood pressure, mean arterial pressure, and higher left ventricular mass index.

In a study exploring the prevalence of LAE and its risk factors in the general population of China, it was noted that female gender, advanced age, and BMI were all risk factors for LAE.[21] In particular, in a report by Stritzke et al.,[22]obesity appeared to be the most important risk factor for LAE in the general population. Evidence showed that epicardial fat was associated with BMI. A correlation between epicardial fat and LA size was also found in the study of lacobellis et al.[22] It is currently hypothesized that epicardial fat is related to the secretion of local pro-inflammatory activity, oxidative stress, and the infiltration and change of atrial cell characteristics and conduction velocity.[23] In view of the increasing prevalence of obesity, early intervention, especially for young obese people, is essential to prevent the premature occurrence of heart remodeling at the atrial level.

The Killip classification was proposed as early as 1967,[24] and the current Killip classification is a useful tool for early risk stratification of acute myocardial infarction(AMI) patients. According to the presence or absence of HF and the severity of hemodynamic changes, HF caused by AMI can be divided into four levels according to Killip classification. As an adaptation to the decreased ventricular compliance after AMI, it will inevitably lead to increased LA internal pressure, increased wall tension, and atrial muscle extension.[25] If there is LAE, the acute LV diastolic and systolic dysfunction caused by AMI can make LA still compensable and eventually mechanical failure. This also further aggravated pump failure. This also 
explains the difference in the proportion of Killip classification between the two groups of subjects in this study. The global registry of acute coronary events (GRACE) risk scoring system is currently one of the most widely used and influential assessment systems for the assessment of the severity of acute coronary syndrome(ACS) conditions worldwide.[26] As we have speculated, the LAdl, like the GRACE score, may predict long-term outcome in patients with STEMI.

The LA, like the LV, undergoes remodeling in response to specific stressors, and, for the LA, the most common cause of remodeling is volume and / or pressure load overload.[10] The LA remodeling responds to altered tissue architecture and electrophysiology. Not only that, myocardial energy production and utilization are altered, and neurohormonal secretion is variably affected.[27] However, unlike the ventricular myocardium, the atrial myocardium cells appear more vulnerable and sensitive when pathologically stimulated. This is also a possible mechanism by which LAE occurs with increased MACEs. In a retrospective cohort study[28] involving 321 patients with HF, it was shown that lad was an independent risk factor for adverse cardiovascular events and that the severity of LAd and HF was positively correlated. Considerable literature suggests that LA is a powerful prognostic indicator in patients with HF, underscoring the importance of utilizing the LA to assess patient outcomes. [29, 30] Moreover, the occurrence and development of AF, considered a marker of atrial structural remodeling, underlies the persistence of AF.[31] Which may be related to the heterogeneity of impulse conduction caused by atrial fibrosis.[31] LAE is not only an independent predictor of AF recurrence,[32-34] relevant literature also points out that LAE would increase the incidence of thrombus formation from the left atrial appendage (LAA) in patients with AF.[35]

Impaired LV systolic and diastolic function are common clinical manifestations of patients after AMI.[36] LV contractility decreases, stroke volume decreases, and the echocardiogram shows a decrease in LVEF and fraction short (FS). The diastolic dysfunction of LV prevents LA emptying and overloads the preload. According to the Frank-Starling law, the above will lead to an increase in the initial length of LA. In the long run, LA will lose its flexibility and eventually lead to LAE. It can be manifested as an increase in LAd, LVEDd, and RVd on the echocardiogram.

Before doing the logistic regression analysis, we made the diagnosis of collinearity. The explanatory variable FS was discarded because of its severe collinearity (VIF > 10) between FS and EF to avoid model distortion.

Our study shows that EF and LAdl are independent risk factors for MACEs, which is consistent with most current studies.[37, 38] Although the American Society of echocardiography recommended to estimate the size of LA with LAV as early as 2005,[6] the complexity of operation limits the application of LAV. Cardiac computed tomography (CCT) and cardiovascular magnetic resonance imaging (CMRI) have their own defects and can not be applied in clinic on a large scale. We excluded patients with hypertension. Although this made us exclude many research objects, we avoided the impact of difficult backtracking of course time, inaccurate medication records and incomplete mastery of blood pressure control in patients with hypertension, making the research results more real and effective. Moreover, we index LAd by BSA to 
further avoid the impact of body shape change on LA, which proves the good prediction ability of LAdl on MACEs. At present, there has been relevant literature that shows that the application of ACEI and ARB treatment can improve the function of LA and reverse the reconstruction of LA,[39] which further illustrates that accurate and repeatable quantitative LA is of great significance in clinical practice.

\section{Conclusion}

LAdl was positively correlated with GRACE score and BNP. The greater the LAdl, the greater the GRACE score and BNP, the worse the prognosis of STEMI patients. LAdl is an independent risk factor for patients with the first diagnosis of STEMI and emergency PCI. Early detection of patients at high risk of STEMI with anti-remodeling therapy can be achieved by evaluating LAdl, administered this morning in the hope of improving long-term outcomes.

$<$

\section{Limitations}

a. The data included in this study were all collected from the first hospital of Jilin University and were single center studies, which only represent part of the subjects in this center.

b. Excluding hypertensive patients although avoiding food mix factors, which severely reduced the sample size. More detailed clinical data on the course, medication, and blood pressure control of hypertensive patients are needed to refine the study.

c. This study did not differentiate between women before and after menopause, and exploration of the factors underlying LAE in women is slightly lacking.

\section{Abbreviations}

$\mathrm{LA}=$ left atrium; $\mathrm{LAE}=$ left atrial enlargement ; LAd=left atrial diameter ; $\mathrm{LAdl}=$ left atrial diameter index; $L A V=l$ eft atrial volume; $L V=$ left ventricular; $R V d=$ right ventricular diameter; IVST= interventricular septal thickness; LVEDd= left ventricular end diastolic diameter; LVPWT= left ventricular posterior wall thickness; $\mathrm{LVEF}=$ left ventricular ejection fraction; $\mathrm{FS}=$ fraction short; $\mathrm{AF}=$ atrial fibrillation; $\mathrm{HF}=$ heart failure; $\mathrm{BSA}=$ body surface area; STEMI= acute ST elevation myocardial infarction; $\mathrm{PCl}=$ percutaneous coronary intervention; $\mathrm{SBP}=$ systolic blood pressure; $\mathrm{DBP}=$ diastolic blood pressure; $\mathrm{HR}=$ heart rate; $\mathrm{Hb}=$ Hemoglobin; $\mathrm{MYO}=$ myoglobin; $\mathrm{CTnl}=$ cardiac troponin I, CK-MB=creatine kinase isoenzymes; $\mathrm{BNP}=\mathrm{B}$-type natriuretic peptide, $D-D=d$ dimer; $C r e=c r e a t i n i n e ; ~ T C=$ total cholesterol; $L D L-C=l o w$-density lipoprotein cholesterol; HDL-C=high-density lipoprotein cholesterol; $T S H=$ thyroid stimulating hormone; $F T 3=3 \llbracket 5 \rrbracket 3^{\prime} \rrbracket$ triiodothyronine; FT4=Free Thyroxine; $\mathrm{ACEl}=$ angiotensin converting enzyme inhibitors; $\mathrm{ARB}=$ angiotensin receptor blocker; MACEs=Major Adverse Cardiovascular Events; $C A D=$ coronary artery disease; $S C D=$ sudden cardiac death $\square$ 


\section{Declarations}

Ethics approval and consent to participate: This study was approved by the medical ethics committee of The First Hospital of Jilin University. All subjects in this trial gave written informed consent.

Consent for publication: Not applicable

Availability of data and material: All data generated or analysed during this study are included in this published article and its supplementary information files.

Conflicts of interest/Competing interests: none

Funding: This study was supported by the Natural Science Foundation of Jilin Province $\$ 20190201035 J C$ to S.Z.区

Authors' contributions: $Y Z$ mainly drafted the analysis and processing of manuscripts and data, $\mathrm{XRH}$ and ZBC were mainly responsible for data collection, MLP, YF and DXY were mainly responsible for data verification and correction of statistical methods, SSZ put forward ideas, checked the final manuscripts and gave suggestions.

Acknowledge: none

\section{References}

1. Mosquera VX, Bouzas-Mosquera A, González-Barbeito M, Bautista-Hernandez V, Muñiz J, AlvarezGarcía N, Cuenca-Castillo JJ. Indexed left atrial size predicts all-cause and cardiovascular mortality in patients undergoing aortic valve surgery. J Thorac Cardiovasc Surg. 2017;153:1275-84.e1277.

2. Abhayaratna WP, Seward JB, Appleton CP, Douglas PS, Oh JK, Tajik AJ, Tsang TS. Left atrial size: physiologic determinants and clinical applications. J Am Coll Cardiol. 2006;47:2357-63.

3. Bombelli M, Cuspidi C, Facchetti R, Sala C, Tadic M, Brambilla G, Re A, Villa P, Grassi G, Mancia G. New-onset left atrial enlargement in a general population. Journal of hypertension. 2016;34:183845 .

4. Su G, Cao H, Xu S, Lu Y, Shuai X, Sun Y, Liao Y, Li J. Left atrial enlargement in the early stage of hypertensive heart disease: a common but ignored condition. J Clin Hypertens (Greenwich). 2014;16:192-7.

5. Canciello G, de Simone G, Izzo R, Giamundo A, Pacelli F, Mancusi C, Galderisi M, Trimarco B, Losi MA. Validation of Left Atrial Volume Estimation by Left Atrial Diameter from the Parasternal Long-Axis View. Journal of the American Society of Echocardiography: official publication of the American Society of Echocardiography. 2017;30:262-9.

6. Lang RM, Bierig M, Devereux RB, Flachskampf FA, Foster E, Pellikka PA, Picard MH, Roman MJ, Seward J, Shanewise JS, Solomon SD, Spencer KT, Sutton MS, Stewart WJ. Recommendations for chamber quantification: a report from the American Society of Echocardiography's Guidelines and 
Standards Committee and the Chamber Quantification Writing Group, developed in conjunction with the European Association of Echocardiography, a branch of the European Society of Cardiology. 18. Journal of the American Society of Echocardiography: official publication of the American Society of Echocardiography; 2005. pp. 1440-63.

7. Inciardi RM, Rossi A. Left atrium: a forgotten biomarker and a potential target in cardiovascular medicine. J Cardiovasc Med. 2019;20:797-808.

8. Delgado V, Di Biase L, Leung M, Romero J, Tops LF, Casadei B, Marrouche N, Bax JJ. Structure and Function of the Left Atrium and Left Atrial Appendage: AF and Stroke Implications. J Am Coll Cardiol. 2017;70:3157-72.

9. Parameswaran R, Kalman JM. Left Atrium and Cardiovascular Risk: Does Functionality Matter More Than Size?, Journal of the American Heart Association, 7 (2018).

10. Triposkiadis F, Pieske B, Butler J, Parissis J, Giamouzis G, Skoularigis J, Brutsaert D, Boudoulas H. Global left atrial failure in heart failure. Eur J Heart Fail. 2016;18:1307-20.

11. Nikitin NP, Witte KK, Thackray SD, Goodge LJ, Clark AL, Cleland JG. Effect of age and sex on left atrial morphology and function. European journal of echocardiography: the journal of the Working Group on Echocardiography of the European Society of Cardiology. 2003;4:36-42.

12. Aurigemma GP, Gottdiener JS, Arnold AM, Chinali M, Hill JC, Kitzman D. Left atrial volume and geometry in healthy aging: the Cardiovascular Health Study. Circ Cardiovasc Imaging. 2009;2:282-9.

13. Fleg JL, Cooper LS, Borlaug BA, Haykowsky MJ, Kraus WE, Levine BD, Pfeffer MA, Piña IL, Poole DC, Reeves GR, Whellan DJ, Kitzman DW. Exercise training as therapy for heart failure: current status and future directions. Circ Heart Fail. 2015;8:209-20.

14. Li H, Hastings MH, Rhee J, Trager LE, Roh JD, Rosenzweig A. Targeting Age-Related Pathways in Heart Failure Circulation research. 2020;126:533-51.

15. Senyo SE, Steinhauser ML, Pizzimenti CL, Yang VK, Cai L, Wang M, Wu TD, Guerquin-Kern JL, Lechene CP, Lee RT. Mammalian heart renewal by pre-existing cardiomyocytes. Nature. 2013;493:433-6.

16. Picca A, Mankowski RT, Burman JL, Donisi L, Kim JS, Marzetti E, Leeuwenburgh C. Mitochondrial quality control mechanisms as molecular targets in cardiac ageing. Nat Rev Cardiol. 2018;15:54354.

17. Yun MH. Cellular senescence in tissue repair: every cloud has a silver lining. Int J Dev Biol. 2018;62:591-604.

18. Cuspidi C, Rescaldani M, Sala C. Prevalence of echocardiographic left-atrial enlargement in hypertension: a systematic review of recent clinical studies. Am J Hypertens. 2013;26:456-64.

19. Wachtell K, Devereux RB, Lyle PA, Okin PM, Gerdts E. The left atrium, atrial fibrillation, and the risk of stroke in hypertensive patients with left ventricular hypertrophy. Ther Adv Cardiovasc Dis. 2008;2:507-13.

20. Proietti M, Raparelli V, Basili S, Olshansky B, Lip GY. Relation of female sex to left atrial diameter and cardiovascular death in atrial fibrillation: The AFFIRM Trial. Int J Cardiol. 2016;207:258-63. 
21. Ou Q, Chen Y, Yu S, Guo X, Zhao H, Sun Y. Prevalence of left atrial enlargement and its risk factors in general Chinese population. BMC Cardiovasc Disord. 2016;16:53.

22. Stritzke J, Markus MR, Duderstadt S, Lieb W, Luchner A, Döring A, Keil U, Hense HW, Schunkert H. The aging process of the heart: obesity is the main risk factor for left atrial enlargement during aging the MONICA/KORA (monitoring of trends and determinations in cardiovascular disease/cooperative research in the region of Augsburg) study. J Am Coll Cardiol. 2009;54:1982-9.

23. Wong CX, Ganesan AN, Selvanayagam JB. Epicardial fat and atrial fibrillation: current evidence, potential mechanisms, clinical implications, and future directions. European heart journal. 2017;38:1294-302.

24. Taguchi E, Konami Y, Inoue M, Suzuyama H, Kodama K, Yoshida M, Miyamoto S, Nakao K, Sakamoto T. Impact of Killip classification on acute myocardial infarction: data from the SAIKUMA registry. Heart vessels. 2017;32:1439-47.

25. Yoon HJ, Jeong MH, Jeong Y, Kim KH, Song JE, Cho JY, Jang SY, Jeong HC, Lee KH, Park KH, Sim DS, Yoon NS, Hong YJ, Park HW, Kim JH, Ahn Y, Cho JG, Park JC, Kang JC. Progressive dilation of the left atrium and ventricle after acute myocardial infarction is associated with high mortality. Korean circulation journal. 2013;43:731-8.

26. Gong IY, Goodman SG, Brieger D, Gale CP, Chew DP, Welsh RC, Huynh T, DeYoung JP, Baer C, Gyenes GT, Udell JA, Fox KAA, Yan AT. GRACE risk score: Sex-based validity of in-hospital mortality prediction in Canadian patients with acute coronary syndrome. Int J Cardiol. 2017;244:24-9.

27. Tsang TS, Abhayaratna WP, Barnes ME, Miyasaka Y, Gersh BJ, Bailey KR, Cha SS, Seward JB. Prediction of cardiovascular outcomes with left atrial size: is volume superior to area or diameter? J Am Coll Cardiol. 2006;47:1018-23.

28. Zhu N, Chen H, Zhao X, Ye F, Jiang W, Wang Y. Left atrial diameter in heart failure with left ventricular preserved, mid-range, and reduced ejection fraction. Medicine. 2019;98:e18146.

29. Inciardi RM, Giugliano RP, Claggett B, Gupta DK, Chandra A, Ruff CT, Antman EM, Mercuri MF, Grosso MA, Braunwald E, Solomon SD. Left atrial structure and function and the risk of death or heart failure in atrial fibrillation. Eur J Heart Fail. 2019;21:1571-9.

30. Malagoli A, Rossi L, Bursi F, Zanni A, Sticozzi C, Piepoli MF, Villani GQ. Left Atrial Function Predicts Cardiovascular Events in Patients With Chronic Heart Failure With Reduced Ejection Fraction. Journal of the American Society of Echocardiography: official publication of the American Society of Echocardiography. 2019;32:248-56.

31. Dzeshka MS, Lip GY, Snezhitskiy V, Shantsila E. Cardiac Fibrosis in Patients With Atrial Fibrillation: Mechanisms and Clinical Implications. J Am Coll Cardiol. 2015;66:943-59.

32. den Uijl DW, Cabanelas N, Benito EM, Figueras R, Alarcón F, Borràs R, Prat S, Guasch E, Perea R, Sitges M, Brugada J, Berruezo A, Mont L. Impact of left atrial volume, sphericity, and fibrosis on the outcome of catheter ablation for atrial fibrillation. J Cardiovasc Electrophys. 2018;29:740-6.

33. Kranert M, Shchetynska-Marinova T, Liebe V, Doesch C, Papavassiliu T, Akin I, Borggrefe M, Hohneck A, Recurrence of Atrial Fibrillation in Dependence of Left Atrial Volume Index, In vivo (Athens, Greece), 
34 (2020) 889-896.

34. Shin SH, Park MY, Oh WJ, Hong SJ, Pak HN, Song WH, Lim DS, Kim YH, Shim WJ. Left atrial volume is a predictor of atrial fibrillation recurrence after catheter ablation. Journal of the American Society of Echocardiography: official publication of the American Society of Echocardiography. 2008;21:697-702.

35. Quan W, Yang X, Li Y, Li J, Ye W, Zhang O, Zhang X. Left atrial size and risk of recurrent ischemic stroke in cardiogenic cerebral embolism. Brain behavior. 2020;10:e01798.

36. Ledwoch J, Stiermaier T, Fuernau G, de Waha S, Eitel C, Pöss J, Desch S, Schuler G, Thiele H, Eitel I. Prognostic Value and Determinants of CMR-Derived Left Atrial Function Assessed in STEMI, JACC. Cardiovascular imaging, 11 (2018) 148-150.

37. Gao F, Huo J, She J, Bai L, He H, Lyu J, Qiang H. Different associations between left atrial size and 2.5-year clinical outcomes in patients with anterior versus non-anterior wall ST-elevation myocardial infarction. J Int Med Res. 2020;48:300060520912073.

38. Stylidis M, Sharashova E, Wilsgaard T, Leon DA, Heggelund G, Rösner A, Njølstad I, Løchen ML, Schirmer H. Left atrial diameter, left ventricle filling indices, and association with all-cause mortality: Results from the population-based Troms $\varnothing$ Study, Echocardiography (Mount Kisco, N.Y.), 36 (2019) 439-450.

39. Kebed KY, Addetia K, Lang RM. Importance of the Left Atrium: More Than a Bystander? Heart Fail Clin. 2019;15:191-204.

\section{Tables}

Table 1: Demographic statistics and baseline clinical characteristics 


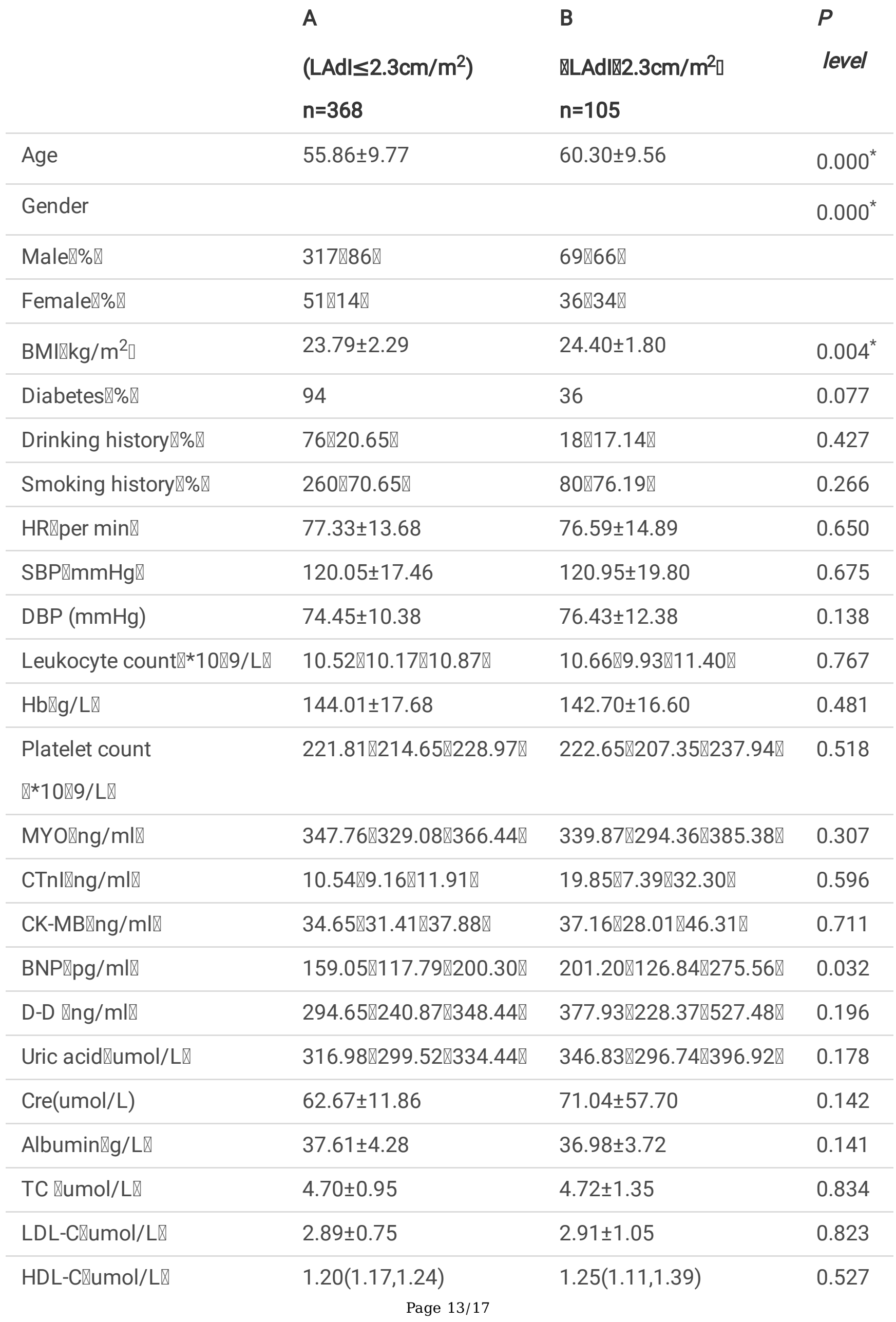




\begin{tabular}{|c|c|c|c|}
\hline Triglyceride(umol/L) & $1.82(1.69,1.95)$ & $1.76(1.51,2.00)$ & 0.608 \\
\hline TSH(ulU/ml) & $1.57(1.41,1.71)$ & $1.65(1.37,1.92)$ & 0.368 \\
\hline FT3(pmol/L) & $4.18 \pm 0.83$ & $4.11 \pm 0.81$ & 0.068 \\
\hline FT4】pmol/L】 & $15.26 \pm 2.68$ & $15.36 \pm 3.05$ & 0.758 \\
\hline Killip & & & $0.000^{*}$ \\
\hline Killip I & $314 \llbracket 85.33 \rrbracket$ & $74 \llbracket 70.48 \rrbracket$ & \\
\hline Killip II & $43 \rrbracket 11.68 \rrbracket$ & $24 \llbracket 22.86 \rrbracket$ & \\
\hline Killip III & $3 \llbracket 0.82 \rrbracket$ & $2 \rrbracket 1.90 \rrbracket$ & \\
\hline Killip IV & $8 \rrbracket 2.17 \rrbracket$ & $5 \rrbracket 4.76 \rrbracket$ & \\
\hline Culprit vessel & & & 0.686 \\
\hline LM(\%) & $3(0.82)$ & $0(0)$ & \\
\hline $\operatorname{LAD}(\%)$ & $187(50.82)$ & $49(46.67)$ & \\
\hline $\operatorname{LCX}(\%)$ & $30(8.15)$ & $11(10.48)$ & \\
\hline $\mathrm{RCA}(\%)$ & $148(40.22)$ & $45(42.86)$ & \\
\hline GRACE score & 81.40ه79.31ه83.49® & $91.07 \rrbracket 87.32 \bowtie 94.81 \rrbracket$ & $0.000^{*}$ \\
\hline GRACE hierarchy & & & $0.001^{*}$ \\
\hline Low risk(\%) & $216(58.70)$ & $44(41.90)$ & \\
\hline Moderate risk(\%) & $143(38.86)$ & $53(50.48)$ & \\
\hline High risk(\%) & $9(2.45)$ & $8(7.62)$ & \\
\hline Aspirin $₫ \% \rrbracket$ & $368 \rrbracket 100 \rrbracket$ & $105 \rrbracket 100 \rrbracket$ & 1.000 \\
\hline Clopidogrel $₫ \% \rrbracket$ & $316 \rrbracket 85.87 \rrbracket$ & $90 \rrbracket 85.71 \rrbracket$ & 0.968 \\
\hline Ticagrelor $\otimes \square$ & $52 \rrbracket 14.13 \rrbracket$ & $15 \rrbracket 14.29 \rrbracket$ & 0.968 \\
\hline Statins $₫ \% \rrbracket$ & $363 \rrbracket 98.64 \rrbracket$ & $105 \rrbracket 100 \rrbracket$ & 0.230 \\
\hline ACEI/ARB $₫ \% \rrbracket$ & 171ه46.47区 & $45 \rrbracket 42.86 \rrbracket$ & 0.513 \\
\hline$\beta$-blockers $₫ \% \rrbracket$ & $246 \rrbracket 66.85 \rrbracket$ & $70 \rrbracket 66.67 \rrbracket$ & 0.972 \\
\hline Diuretic®\%】 & $209 \otimes 56.79 \rrbracket$ & $61 \rrbracket 58.10 \rrbracket$ & 0.812 \\
\hline
\end{tabular}

${ }^{*}=P \otimes 0.05 \bigotimes$ The difference was statistically significant. 
$\mathrm{HR}=$ heart rate; $\mathrm{SBP}=$ systolic blood pressure; $\mathrm{DBP}=$ diastolic blood pressure; $\mathrm{Hb}=$ Hemoglobin; $\mathrm{MYO}=$ myoglobin; $\mathrm{CTnI}=$ cardiac troponin $\mathrm{I}, \mathrm{CK}-\mathrm{MB}=$ creatine kinase isoenzymes; $\mathrm{BNP}=\mathrm{B}$-type natriuretic peptide, $D-D=d$ dimer; Cre=creatinine; $T C=$ total cholesterol; LDL-C=low-density lipoprotein cholesterol; HDL-C=high-

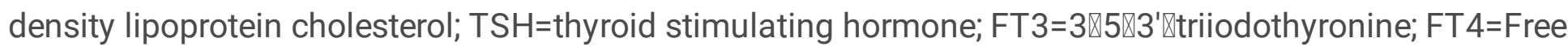
Thyroxine; $\mathrm{ACEl}=$ angiotensin converting enzyme inhibitors; $\mathrm{ARB}=$ angiotensin receptor blocker.

\section{Table 2. Echocardiographic features}

\begin{tabular}{|c|c|c|c|}
\hline & A & B & $P$ \\
\hline & $\left(\mathrm{LAdl} \leq 2.3 \mathrm{~cm} / \mathrm{m}^{2}\right)$ & 邓LAdIख $2.3 \mathrm{~cm} / \mathrm{m}^{2} \square$ & level \\
\hline & $n=368$ & $n=105$ & \\
\hline $\operatorname{LAd}(\mathrm{mm})$ & $33.70(33.36,34.04)$ & $42.90(41.81,44.00)$ & $0.000^{\star}$ \\
\hline $\mathrm{RVd}(\mathrm{mm})$ & $21.65(21.37,21.94)$ & $22.56(22.06,23.06)$ & $0.002^{*}$ \\
\hline IVST(mm) & $8.88(8.76,9.00)$ & $9.11(8.85,9.38)$ & 0.155 \\
\hline LVEDd(mm) & $49.97 \pm 4.00$ & $52.27 \pm 24.35$ & $0.000^{*}$ \\
\hline LVPWT囚mm® & $8.61 \rrbracket 8.52 \llbracket 8.71 \rrbracket$ & $8.67 \rrbracket 8.45 \llbracket 8.88 \rrbracket$ & 0.614 \\
\hline LVEF®\%区 & $52.00 \rrbracket 51.28 \rrbracket 52.72 \rrbracket$ & $49.67 \rrbracket 47.98 \rrbracket 51.36 \rrbracket$ & $0.009^{*}$ \\
\hline FS & $26.79 \llbracket 26.36 \rrbracket 27.22 \rrbracket$ & $25.47 \rrbracket 24.57 \rrbracket 26.36 \rrbracket$ & $0.006^{*}$ \\
\hline$E / A$ & $1.06(1.02,1.10)$ & $1.11(1.02,1.21)$ & 0.674 \\
\hline
\end{tabular}

${ }^{*}=P \otimes 0.05 \bigotimes$ The difference was statistically significant.

LAd=left atrial diameter; RVd=right ventricular diameter; IVST= interventricular septal thickness; LVEDd= left ventricular end diastolic diameter; LVPWT= left ventricular posterior wall thickness;

LVEF= left ventricular ejection fraction; $F S=$ fraction short.

Table 3. The relationship between LAdl and BNP and the GRACE score

\begin{tabular}{lll} 
& GRACE score( $r)$ & P level \\
\hline LAdl & 0.284 & $0.000^{\star}$ \\
\hline & BNP $(r)$ & $P$ level \\
\hline LAdl & 0.107 & $0.020^{*}$
\end{tabular}


${ }^{*}=P \otimes 0.05 \bigotimes$ The difference was statistically significant.

Table 4. The characteristics of maces in the two groups

\begin{tabular}{llll} 
& A & B & $P$ \\
& $\left(\right.$ LAdl $\left.\leq 2.3 \mathrm{~cm} / \mathrm{m}^{2}\right)$ & QLAdIX2.3cm/m² & level \\
& $\mathrm{n}=368$ & $\mathrm{n}=105$ & \\
\hline MACEs(\%) & $130(36.11)$ & $65(61.90)$ & $0.000^{*}$ \\
\hline $\mathrm{AF}(\%)$ & $11(2.99)$ & $18(17.14)$ & $0.000^{*}$ \\
\hline $\mathrm{HF}(\%)$ & $65(17.66)$ & $32(30.48)$ & $0.004^{*}$ \\
\hline Readmission for CAD(\%) & $76(20.65)$ & $24(22.86)$ & 0.626 \\
\hline $\mathrm{SCD}(\%)$ & $10(2.72)$ & $6(5.71)$ & 0.134
\end{tabular}

${ }^{*}=P \otimes 0.05 \bigotimes$ The difference was statistically significant.

MACEs=Major Adverse Cardiovascular Events; $\mathrm{AF}=$ atrial fibrillation; $\mathrm{HF}=$ heart failure; $\mathrm{CAD}=$ coronary artery disease; $S C D=$ sudden cardiac death.

Table 5. Results of logistic regression analysis of MACEs 


\begin{tabular}{llllllll} 
& \multirow{2}{*}{$\beta$} & & S.E. & Odds Ratio & \multicolumn{2}{l}{$95.0 \% \mathrm{Cl}$} & $P$ \\
\cline { 1 - 3 } & & & & Lower & Upper & level \\
\cline { 1 - 3 } Gender & -0.008 & 0.322 & 0.992 & 0.528 & 1.864 & 0.981 \\
\hline Age & -0.009 & 0.027 & 0.991 & 0.939 & 1.046 & 0.742 \\
\hline BMI & 0.094 & 0.056 & 1.099 & 0.985 & 1.225 & 0.091 \\
\hline LAdI & 1.938 & 0.818 & 6.945 & 1.398 & 34.499 & $0.018^{*}$ \\
\hline RVd & -0.020 & 0.038 & 0.981 & 0.911 & 1.056 & 0.606 \\
\hline IVS & 0.121 & 0.136 & 1.129 & 0.864 & 1.473 & 0.374 \\
\hline LVEDd & -00.032 & 0.027 & 0.968 & 0.918 & 1.021 & 0.237 \\
\hline LAd & -0.022 & 0.049 & 0.978 & 0.888 & 1.076 & 0.646 \\
\hline LVPWT & -0.325 & 0.167 & 0.723 & 0.521 & 1.003 & 0.052 \\
\hline EA & -0.218 & 0.245 & 0.804 & 0.498 & 1.299 & 0.373 \\
\hline EF & -0.071 & 0.015 & 0.931 & 0.904 & 0.960 & $0.000^{*}$ \\
\hline GRACE score & 0.002 & 0.013 & 1.002 & 0.976 & 1.029 & 0.870
\end{tabular}

${ }^{*}=P \otimes 0.05 \bigotimes$ The difference was statistically significant.

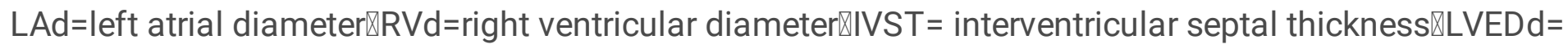

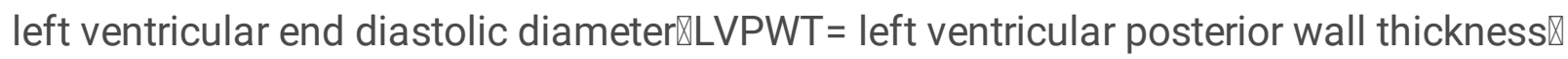

$L V E F=$ left ventricular ejection fraction $\mathbb{F S}=$ fractional shortening. 